\title{
Provision of carbon skeleton for lipid synthesis from the breakdown of intracellular protein and soluble sugar in Phaeodactylum tricornutum under high $\mathrm{CO}_{2}$
}

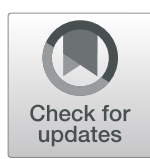

Aiyou Huang ${ }^{1,2,3}$, Songcui $\mathrm{Wu}^{1,2,3}$, Wenhui Gu${ }^{1,2,3}$, Yuanxiang $\mathrm{Li}^{1,2,3}$, Xiujun Xie $\mathrm{X}^{1,2,3}$ and Guangce Wang ${ }^{1,2,3^{*}}$ (D)

\begin{abstract}
Background: Increasing $\mathrm{CO}_{2}$ emissions have resulted in ocean acidification, affecting marine plant photosynthesis and changing the nutrient composition of marine ecosystems. The physiological and biochemical processes of marine phytoplankton in response to ocean acidification have been reported, but have been mainly focused on growth and photosynthetic physiology. To acquire a thorough knowledge of the molecular regulation mechanisms, model species with clear genetic background should be selected for systematic study. Phaeodactylum tricornutum is a pennate diatom with the characteristics of small genome size, short generation cycle, and easy to transform. Furthermore, the genome of $P$. tricornutum has been completely sequenced.

Results and discussion: In this study, P. tricornutum was cultured at high and normal $\mathrm{CO}_{2}$ concentrations. Cell composition changes during culture time were investigated. The ${ }^{13} \mathrm{C}$ isotope tracing technique was used to determine fractional labeling enrichments for the main cellular components. The results suggested that when lipid content increased significantly under high $\mathrm{CO}_{2}$ conditions, total protein and soluble sugar contents decreased. The ${ }^{13} \mathrm{C}$ labeling experiment indicated that the $\mathrm{C}$ skeleton needed for fatty acid $\mathrm{C}$ chain elongation in lipid synthesis under high $\mathrm{CO}_{2}$ conditions is not mainly derived from $\mathrm{NaHCO}_{3}$ (carbon fixed by photosynthesis).

Conclusion: This study indicated that breakdown of intracellular protein and soluble sugar provide $\mathrm{C}$ skeleton for lipid synthesis under high $\mathrm{CO}_{2}$ concentration.
\end{abstract}

Keywords: Phaeodactylum tricornutum, Lipid, High $\mathrm{CO}_{2}$ concentration, Origin of carbon skeleton

\section{Background}

Increased $\mathrm{CO}_{2}$ emissions have caused ocean acidification, which has greatly affected the photosynthesis process of marine plants. Ocean acidification has not only increased photosynthetic and respiration rates [1], and down regulated the carbon concentration mechanism [2], but also influenced nutrition uptake, and altered the $\mathrm{C} / \mathrm{N}$ ratio and cell composition in marine phytoplankton [3, 4]. Since marine phytoplankton are the main primary producers in the ocean, changes in their

\footnotetext{
*Correspondence: gcwang@qdio.ac.cn

'Key Laboratory of Experimental Marine Biology, Institute of Oceanology, Chinese Academy of Sciences, Qingdao 266071, China

'Laboratory for Marine Biology and Biotechnology, Qingdao National Laboratory for Marine Science and Technology, Qingdao 266071, China Full list of author information is available at the end of the article
}

biomass and cell composition will influence the nutritional status of marine zooplankton. Therefore, it is of great importance to study phytoplankton growth and cell composition changes under high $\mathrm{CO}_{2}$ conditions. For systematic research, it is important to select model species with a clear genetic background, that are easy to transform, and perform in metabolic flow analysis.

As the main components of marine phytoplankton, marine diatoms produce approximately $20 \%$ of global primary productivity and play an important role in inorganic $C$ fixation and material cycles [5, 6]. Phaeodactylum tricornutum is a pennate diatom with the characteristics of small genome size, short generation cycle, and easy to transform [7]. Since its whole genome sequencing has been completed [8], it has clear genetic background and is 
one of the most promising candidates for studying photosynthetic physiology in single-cell algae. P. tricornutum is rich in polyunsaturated fatty acids and can therefore be used as food for aquaculture animals [9]. It has the potential to be used as raw biodiesel materials as it can accumulate oil under conditions such as nitrogen deficiency [10]. Its main pigment is fucoxanthin, which is reported to have antioxidant, cancer prevention, free radical scavenging, and weight loss effects [11]. Therefore, the study of the C flow distribution mechanism in P. tricornutum under high $\mathrm{CO}_{2}$ has not only fundamental research significance but also important application value.

The physiological and biochemical responses of $P$. tricornutum under high $\mathrm{CO}_{2}$ have been reported. Wu et al. (2010) found that under short term exposure to high $\mathrm{CO}_{2}$ concentration, the growth, photosynthetic, and respiration rates of $P$. tricornutum increased, while carbon concentrating mechanism activity decreased [12]. After long-term adaptation, growth and respiration rate have been shown to decrease [13]. Li et al. (2012) found that high $\mathrm{CO}_{2}$ had no effect on the growth of P. tricornutum [14]. These inconsistent results might be caused by different light intensities.Besides, stress such as C-limitation might also trigger modifications of the carbon flow in P. triconutom $[15,16]$. These results suggest that factors such as culture time, light intensity, and nutritional status can affect the response of $P$. tricornutum to high $\mathrm{CO}_{2}$, which are important for revealing the physiological and ecological processes of marine diatoms under high $\mathrm{CO}_{2}$. However, since this research is limited to growth and photosynthetic physiology only, the molecular mechanism of the response process is not fully understood. Based on genomic data, Levering et al. (2017) integrated the metabolic network and regulation mode of $P$. tricornutum, and predicted its global regulation mechanism under different $\mathrm{CO}_{2}$ concentrations $(400 \mathrm{ppm}$ and $5,000 \mathrm{ppm})$ at the transcriptome level [17]. To verify these predictions, a large number of experiments should be conducted.

In a previous study, the current authors found that the growth rate, lipid content, and fucoxanthin content of $P$. tricornutum were significantly increased in short-term culture under high $\mathrm{CO}_{2}(2,000 \mathrm{ppm})$. The key enzymes of the Calvin cycle and pentose phosphate pathway were elevated at both transcriptional and enzymatic levels [18]. This suggested that $P$. tricornutum readjusts central $\mathrm{C}$ metabolism under high $\mathrm{CO}_{2}$, and supplements its growth and lipid synthesis by high-speed operation of pentose phosphate pathway. These results provide theoretical and technical support for the study the response of $P$. tricornutum to high $\mathrm{CO}_{2}$. However, the molecular mechanism of its response process has not been comprehensively analyzed, and further research is needed.
In this study, $P$. tricornutum was cultured at different $\mathrm{CO}_{2}$ concentrations. Changes in cell composition with culture time were determined. The ${ }^{13} \mathrm{C}$ isotope tracing technique was used to detect the origin of $\mathrm{C}$ skeletons. This study reveals the $\mathrm{C}$ flow distribution mechanism of $P$. tricornutum in response to high $\mathrm{CO}_{2}$ concentration.

\section{Results}

Influence of $\mathrm{CO}_{2}$ concentration on growth

The growth rate of $P$. tricornutum showed significant differences under $\sim 400 \mathrm{ppm}$ of $\mathrm{CO}_{2}(\mathrm{NC})$ or high $\mathrm{CO}_{2}$ of $\sim 2,000 \mathrm{ppm}$ (HC) (Fig. 1). Under HC, $\mathrm{A}_{730 \mathrm{~nm}}$ was 0.20 at the beginning of inoculation, $\sim 0.80$ on D6, and $\sim 1.21$ on D10. Under $\mathrm{NC}, \mathrm{A}_{730 \mathrm{~nm}}$ was $\sim 0.20$ at the beginning of inoculation, $\sim 0.57$ on D6, and $\sim 0.87$ on D10. These results were consistent with a previous study [18].

\section{Changes in cell composition with culture time under HC and NC \\ Total lipid content}

Total lipid content changed relatively little at the beginning of cultivation (within 6 days after inoculation) under both $\mathrm{HC}$ and NC. After 8 days of cultivation, total lipid content increased a little under NC, but was significantly enhanced under HC (Fig. 2a). This was consistent with previous findings [18]. During the entire cultivation, total lipid content was higher under $\mathrm{HC}$ than under $\mathrm{NC}$ at the same time point.

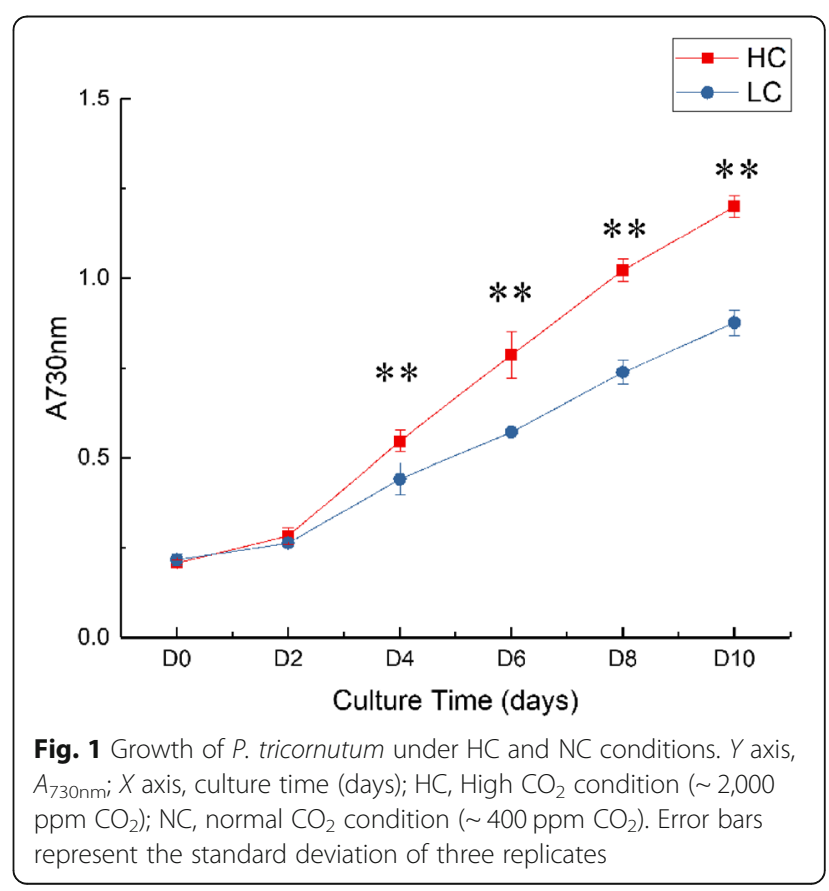



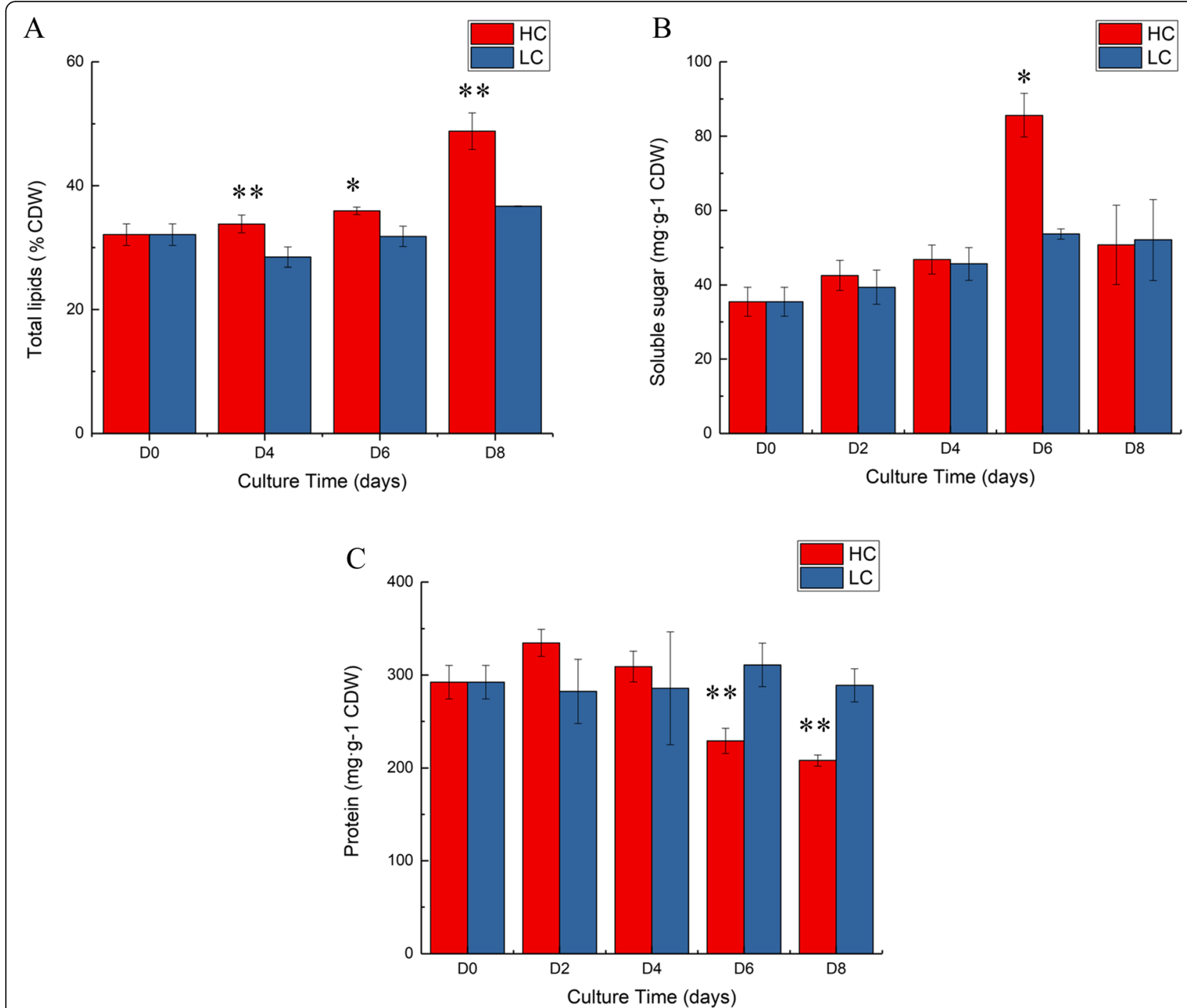

Fig. 2 Changes of major cell compositions with culture time under HC and NC conditions. a. Changes in total lipid content. b. Changes in total soluble sugar. c. Changes in total protein content. $Y$ axis, \% cell dried weight (\%CDW) for total lipid and $\mathrm{mg} \cdot \mathrm{g}^{-1}$ for sugar and protein; $X$ axis, culture time (days). Error bars represent the standard deviation of three replicates

\section{Soluble sugar content}

Under NC, soluble sugar content increased gradually within 8 days after inoculation. While under $\mathrm{HC}$, soluble sugar content increased sharply within 6 days after inoculation, then decreased significantly on D8. There was little difference between soluble sugar content under $\mathrm{HC}$ and NC during the entire cultivation, except on D6, when soluble sugar content under $\mathrm{HC}$ was significantly higher than that under NC (Fig. 2b).

\section{Total protein content}

Under NC, total protein content changed little within 8 days after inoculation. While under $\mathrm{HC}$, total protein content increased a little on D4, then decreased gradually on D6. On D8, total protein content decreased significantly under $\mathrm{HC}$. On D2, total protein content under $\mathrm{HC}$ was higher than that under NC. While on D6 and D8, it was significantly lower than that under NC (Fig. 2c).

\section{Fractional labeling s of major cellular components under} $\mathrm{HC}$ and $\mathrm{NC}$

To determine the main $\mathrm{C}$ flow of photosynthesis and to track the origin (de novo synthesis through photosynthesis or degradation of intracellular substances) of the C skeleton of the major cellular components, the ${ }^{13} \mathrm{C}$ isotope tracing technique was used and the (fractional labeling) FLs of major cellular components under HC and $\mathrm{NC}$ were analyzed. In general, for the same substance, the FL was higher under NC than under HC. 


\section{Fractional labeling of lipids}

To analysis the FLs of total lipids, total lipids were derivatized to butyl amides and the FLs of fatty acids were measured. Based on GC-MS, five fatty acids were detected. Among these, stearic acid was detected throughout all samples, and its abundance was much higher than that of the other fatty acids. Therefore, its FL was used to represent the FLs of lipids. Cells on D1, D3, D5, and D7 were labelled and sampled on D2, D4, D6, and D8 (1 day after labelling), respectively. Under $\mathrm{HC}$, the $\mathrm{FL}$ of stearic acid increased a little on D4. After that, the FL decreased with increasing culture time. The FL on D8 ( 0.045) was significantly lower than that on D2 $(\sim 0.131)$. Under NC, the FL increased on D4 and D6. On D8 The FL decreased to $~ 0.083$ (Fig. 3a).

\section{Fractional labeling of soluble sugar}

To analysis the FL of soluble sugar, soluble sugar was converted into monosaccharides by hydrolysis. Monosaccharide was then derivatized by Bis(trimethylsilyl) trifluoroacetamide. The FL of glucose was measured and used to represent the FL of soluble sugar. Under HC, the FL was $~ 0.176$ on D2, increased significantly on D4 ( 0.217), then decreased rapidly on D6 (0.103). On D8, FL was $~ 0.083$. The changing trend of $\mathrm{FL}$ under $\mathrm{NC}$ was similar to that under $\mathrm{HC}$, except that the level was higher under $\mathrm{NC}$ at the same time point. On D8, the FL was still 0.229 under NC (Fig. 3c).

\section{Fractional labeling of protein}

To analyze the FLs of protein, total protein was converted into amino acids by hydrolysis. Amino acids were then derivatized by $\mathrm{N}$-tert-butyldimethylsilyl-N-methyltrifluoroacetamide. The average FL of all amino acids was used to represent the FL of total protein (Fig. 3b). Under HC, the FL was high only on D2 $(\sim 0.179)$, then it decreased significantly on D4 $(\sim 0.036)$. On D8, the FL was very low $(\sim 0.022)$. Under $\mathrm{NC}$, the FL was high on

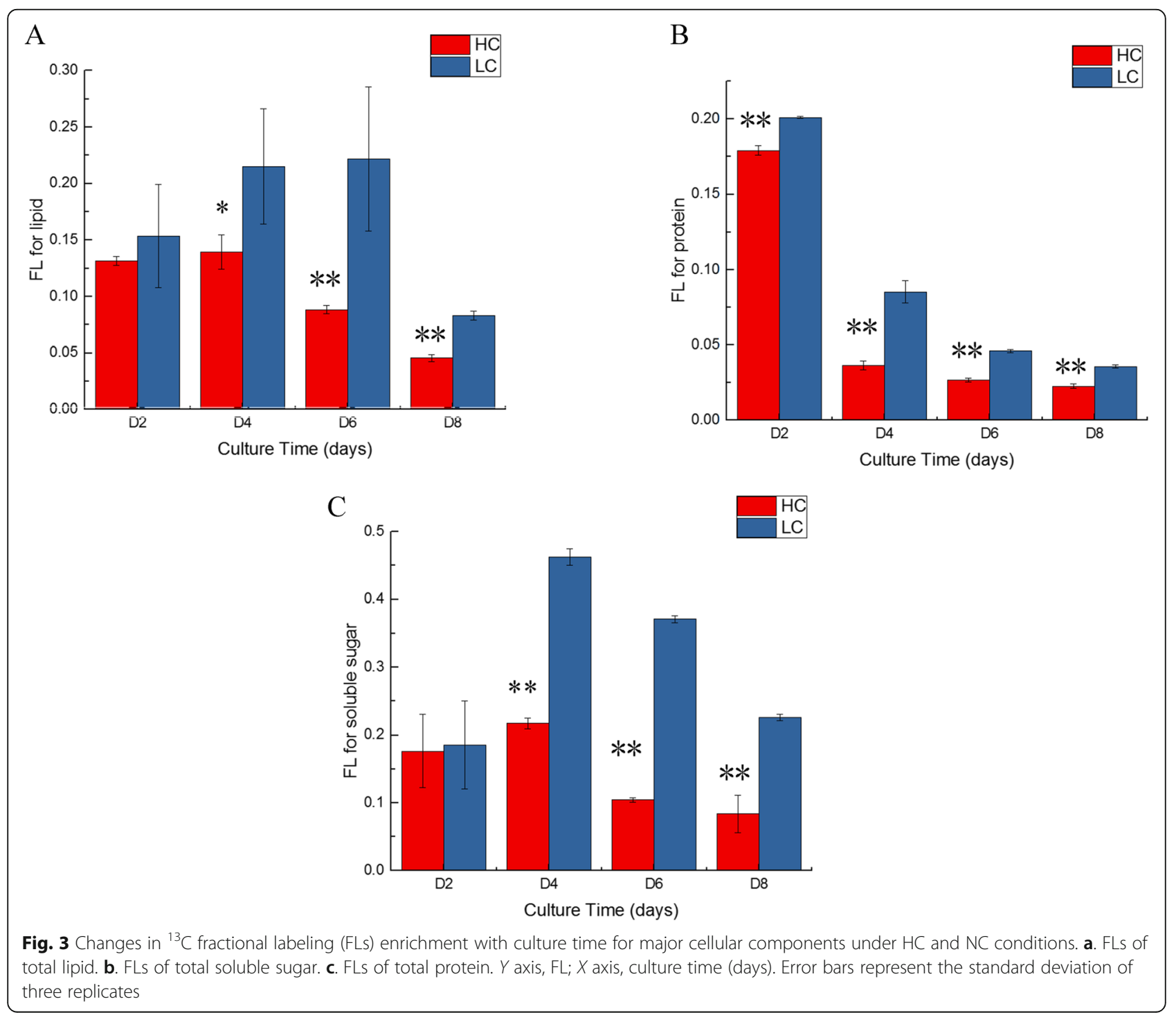


D2 ( 0.201), then decreased on D4 ( 0.085) and D6 ( $0.046)$. On D8, the FL was very low $(\sim 0.035)$.

\section{Nitrate concentration in the medium}

We measured the concentration of nitrate concentration in the medium. The results showed that nitrate in the $\mathrm{HC}$ group and the NC group were exhausted on D4 and D6, respectively (Fig. 4). That is, HC P. tricornutum was exposed to nitrogen deficiency earlier than in NC.

\section{Discussion}

\section{High $\mathrm{CO}_{2}$ and nitrogen deficiency might prompt lipid} accumulation

With the rapid growth of $P$. tricornutum under $\mathrm{HC}$, abundant nitrogen must be consumed. With the prolongation of culture time, the nitrogen source in the medium would be gradually exhausted. Nitrate was exhausted earlier under $\mathrm{HC}$ (Fig. 4). We speculated that nitrogen deficiency stress is the switch that triggers the adjustment of central $C$ metabolism and the start of lipid accumulation in $P$. tricornutum under HC. In our previous study we detected the $\mathrm{pH}$ of the growth medium and found that under $\mathrm{NC}$ the medium $\mathrm{pH}$ increased gradually from 8.83 to 9.41. Under $\mathrm{HC}$ the $\mathrm{pH}$ decreased on day 1 and then gradually increased to 8.32 [18]. Differences in $\mathrm{pH}$ would influence the dissolution of $\mathrm{CO}_{2}$. These factors might also impact lipid accumulation under $\mathrm{HC}$ and NC.

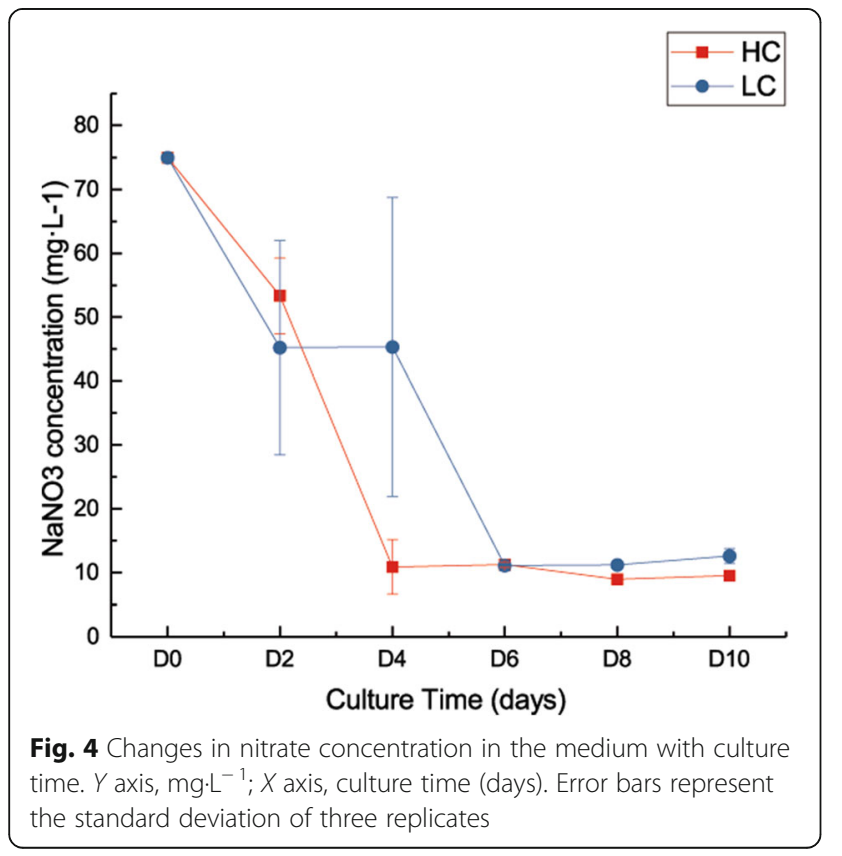

\section{P. tricornutum provides $\mathrm{C}$ skeleton for lipid synthesis by} degradation of soluble sugar and protein under $\mathrm{HC}$ The changes in soluble sugar, total lipids, and protein contents were further compared under $\mathrm{HC}$ and $\mathrm{NC}$ concentrations. Under $\mathrm{HC}$, the contents of total lipids increased on D8, while the contents of soluble sugars and proteins initially increased and then decreased on D8. Under NC, the contents of total lipids and protein changed relatively little, while the contents of soluble sugars increased gradually. These results suggest that under HC P. tricornutum might provide $C$ skeleton for lipid synthesis through degradation of soluble sugars and proteins.

\section{${ }^{13} \mathrm{C}$ labeling experiment provided additional evidence for the origin of $\mathrm{C}$ skeleton for fatty acid synthesis under $\mathrm{HC}$} In order to trace the origin of $\mathrm{C}$ skeleton for various cell components, $P$. tricornutum was labelled at different time points during cultivation and the labeling degree of soluble sugar, total lipids, and protein was determined. In general, if the cell is labeled at a time point when the synthesis of one substance was vigorous, then the labeling degree of the corresponding substance is high.

Under $\mathrm{HC}$, the protein content increased on D2, then decreased significantly. This indicated that protein synthesis was vigorous at the beginning 2 days of cultivation. Accordingly, the labeling degree of amino acids under $\mathrm{HC}$ was the highest on D2 $(\sim 0.176)$, then decreased significantly to $\sim 0.036$ on D4. On D6 and D8, the values were $\sim 0.026$ and $\sim 0.022$, respectively, which was similar to the value of unlabeled cells. This indicated that under $\mathrm{HC}$, de novo synthesized amino acids through photosynthetic $\mathrm{C}$ fixation decreased after D4. Under NC, protein content changed relatively little. Accordingly, the labeling degree of amino acids was maintained above 0.04 at the beginning 6 days after cultivation. On D8, the value decreased to $\sim 0.036$. This indicated that on $\mathrm{D} 8$, de novo synthesized amino acids through photosynthetic $\mathrm{C}$ fixation decreased.

Under $\mathrm{HC}$, the soluble sugar content increased within 6 days after inoculation and then decreased on D8. Accordingly, the labeling degree of sugar was highest on D4 (0.217) and then decreased to 0.104 on D6. This indicated that de novo synthesized sugar through photosynthetic C fixation had decreased on D6. On D8, the value was $\sim 0.083$, indicating that there was still a small part of sugar was de novo synthesized through photosynthetic $\mathrm{C}$ fixation. Under $\mathrm{NC}$, the soluble sugar content increased rapidly initially and then stabilized. Correspondingly, the labeling degree of sugar increased rapidly on $\mathrm{D} 4$ (from $\sim 0.185$ to $\sim 0.463$ ), then decreased slowly. On D8, the value was still 0.231 , indicating that sugar de novo synthesis remained in progress. 
This was not the case for lipids. Under $\mathrm{NC}$, total lipid content did not change much within 6 days of culture. Consistently, the labeling degree did not change much. However, on D8, when total lipid content increased slightly, the labeling degree did not increase but decreased significantly to $\sim 0.083$. Under $\mathrm{HC}$, total lipid content increased significantly on D8, yet the labeling degree decreased to $\sim 0.045$. This indicated that the $\mathrm{C}$ skeleton needed for fatty acid $\mathrm{C}$ chain elongation in lipid synthesis under $\mathrm{HC}$ is not mainly derived from $\mathrm{NaHCO}_{3}$ ( $\mathrm{C}$ fixed by photosynthesis), but from the degradation of intracellular substances (such as proteins and soluble sugars).

\section{Conclusions}

This study indicated that the degradation of intracellular substances (such as proteins and soluble sugars) provide the $\mathrm{C}$ skeleton needed for fatty acid $\mathrm{C}$ chain elongation in lipid synthesis under $\mathrm{HC}$.

\section{Methods}

\section{Strains and culture conditions}

Axenic cultures of P. tricornutum (IOCAS-001) were maintained in the laboratory [19]. Cells were cultivated with conditions described previously [19] $\left(20^{\circ} \mathrm{C}\right.$, $\sim 100 \mu \mathrm{mol} \mathrm{m}^{-2} \mathrm{~s}^{-1} \mathrm{cool}$ white fluorescent light, 12 $/ 12 \mathrm{~h}$ light-dark cycle) in artificial seawater $\left(\mathrm{NaHCO}_{3}\right.$ was not contained) [20] with $\mathrm{f} / 2$ [21] inorganic nutrients (containing $75 \mathrm{mg} \mathrm{L}^{-1} \mathrm{NaNO}_{3}, 5 \mathrm{mg} \mathrm{L}^{-1} \mathrm{NaH}_{2}$ $\mathrm{PO}_{4} \cdot 2 \mathrm{H}_{2} \mathrm{O}, \quad 3.2 \mathrm{mg} \mathrm{L}^{-1} \quad \mathrm{FeCl}_{3} \cdot 6 \mathrm{H}_{2} \mathrm{O}, \quad 1.8 \mathrm{mg} \mathrm{L}^{-1}$ EDTANa $\left.2,20 \mathrm{mg} \mathrm{L}^{-1} \mathrm{Na}_{2} \mathrm{SiO}_{3} \cdot 9 \mathrm{H}_{2} \mathrm{O}\right)$, trace elements, and vitamins (filter-sterilized). The initial $\mathrm{pH}$ was 8.8 and was not controlled in the process of cultivation. Cell growth was monitored as described [18, 19]. For $\mathrm{CO}_{2}$ treatment, cultures were cultivated with 1.5-L medium in 2-L flasks, continuously aerated with air (containing $\sim 400 \mathrm{ppm} \mathrm{CO}_{2}, \mathrm{NC}$ ) or with a mixture gas of air and $\mathrm{CO}_{2}$ (containing $\sim 2000 \mathrm{ppm} \mathrm{CO}_{2}$, $\mathrm{HC}$ ) at a constant flow rate of $\sim 150 \mathrm{ml} \mathrm{min}^{-1}$. There were three replicates for each treatment. For cell composition analysis, cells were harvested at 2 days, 4 days, 6 days, and 8 days after inoculation (D2, D4, D6, and D8, respectively). After $5,000 \mathrm{~g}$ centrifugation for $4 \mathrm{~min}$ at $20^{\circ} \mathrm{C}$, the cell pellet washed with steam-sterilized artificial seawater, and then frozen immediately in liquid nitrogen and stored at $-80^{\circ} \mathrm{C}$.

\section{${ }^{13} \mathrm{C}$ labeling experiment}

Cultures were grown in four replicates in 2-L flasks containing $1.5-\mathrm{L}$ medium. For ${ }^{13} \mathrm{C}$ labeling, ${ }^{13} \mathrm{C}-\mathrm{NaHCO}_{3}$ (Cambridge Isotope Laboratories) was added to a final concentration of $0.174 \mathrm{~g} \mathrm{l}^{-1}$ to flasks No.1, No.2, No.3, and No.4 at D1, D3, D5, and D7, respectively. Samples were collected at 1 day after labeling (D2, D4, D6, and D8) as described above.

\section{Sample preparation and GC-MS analysis}

GC-MS was performed with an Agilent 6890-5973 GC-MS system. Agilent HP-5MS column (30 $\mathrm{m} \times$ $0.25 \mathrm{~mm} \times 0.25 \mu \mathrm{m})$ was equipped and $\mathrm{He}$ was the carrier gas.

Analysis of sugar labelling enrichment was conducted as described previously [22]. Briefly, the labelled samples were hydrolyzed with $6 \mathrm{moll}^{-1} \mathrm{HCl}$ at $110{ }^{\circ} \mathrm{C}$ for $3 \mathrm{~h}$ and dried at $\sim 80^{\circ} \mathrm{C}$ overnight, dissolved in $100 \mu \mathrm{L}$ of anhydrous pyridine, and then derivatized with $50 \mu \mathrm{L}$ of Bis(trimethylsilyl) trifluoroacetamide. The reaction was conducted at $70{ }^{\circ} \mathrm{C}$ for $3 \mathrm{~h}$. After centrifuged at $10,000 \mathrm{~g}$ for $5 \mathrm{~min}$, the supernatant was collected and filtered with $0.22 \mu \mathrm{m}$ pore size filters. GC-MS was performed as previously described [22, 23].

For labelling enrichment analysis of protein, samples were hydrolyzed with $6 \mathrm{moll}^{-1} \mathrm{HCl}$ at $110^{\circ} \mathrm{C}$ for $12 \mathrm{~h}$, dried overnight under $\sim 80^{\circ} \mathrm{C}$, and dissolved in $100 \mu \mathrm{L}$ of anhydrous pyridine, and then derivatized with $50 \mu \mathrm{L}$ of N-tert-butyldimethylsilyl-Nmethyltrifluoroacetamide. The reaction was conducted at $85^{\circ} \mathrm{C}$ for $60 \mathrm{~min}$ and centrifuged and filtered as described above. GC-MS was performed as previously described [19, 23].

For labelling enrichment analysis of lipids, $1 \mathrm{ml}$ hexane was added to $\sim 5 \mathrm{mg}$ freeze-dried algal powder, stirred vigorously for $5 \mathrm{~min}$, and centrifugated at $8,000 \mathrm{~g}$ for $5 \mathrm{~min}$. The supernatant was recovered and the process repeated three times. Hexane aliquots were combined and evaporated at $\sim 20^{\circ} \mathrm{C}$. Butyl amide reactions were performed as previously described [24]. $20 \mu \mathrm{L}$ of standards (triolein, tripalmitin, or tristearin with a concentration of $25 \mu \mathrm{L} / \mathrm{mL}$ ) or total lipids extracted from $5 \mathrm{mg}$ cell pellets were dissolved in $3 \mathrm{ml}$ hexane, mixed with $2 \mathrm{ml} \mathrm{n}$-butylamine, and maintained at $\sim 70{ }^{\circ} \mathrm{C}$ for $48 \mathrm{~h}$. A $1 \mathrm{~mL}$ sample of $4 \mathrm{M} \mathrm{HCl}$ was added to quench the reaction. The hexane phase was recovered and analyzed by GC-MS [24].

\section{GC-MS data processing}

The GC-MS data were analyzed as described previously [23, 25-27]. The mass isotopomer distribution vector (MDV) for fragments from glucose, amino acids, and fatty acids were assigned according to formula (1). The natural abundance of stable isotopes of $\mathrm{C}, \mathrm{N}, \mathrm{O}, \mathrm{H}, \mathrm{Si}$, and $\mathrm{S}$ were corrected and the fractional labeling enrichments (FL) were calculated according to formula (2). 


$$
\begin{aligned}
& M D V a=\left[\begin{array}{c}
\left(m_{0}\right) \\
\left(m_{1}\right) \\
\vdots \\
\left(m_{n}\right)
\end{array}\right] \text { with } \sum_{i=0}^{n} m_{i}=1 \\
& F L=\frac{\sum_{i=0}^{n} i \cdot m_{i}}{n \cdot \sum_{i=0}^{n} m_{i}}
\end{aligned}
$$

\section{Total lipid analysi}

Total lipids content was determined as described previously [28, 29]. Briefly, $1 \mathrm{ml}$ of methanol/chloroform (1:1) was added to $\sim 10 \mathrm{mg}$ freeze-dried cells, stirred vigorously for $5 \mathrm{~min}$, and mixed with $0.3 \mathrm{ml}$ of $0.2 \mathrm{M} \mathrm{H}_{3} \mathrm{PO}_{4}$ (containing $1 \mathrm{M} \mathrm{KCl}$ ). The mixture was centrifugated for $5 \mathrm{~min}$ at $5,000 \mathrm{~g}$ and the solvent phase was recovered. After three times of extraction, the solvent phases were combined, washed with distilled water for three times, and then evaporated at $\sim 20^{\circ} \mathrm{C}$ within a fume hood. The total lipid content was weighed and expressed as \% cell dry weight (CDW).

\section{Total soluble sugar analysis}

Total soluble sugar content was analyzed as described previously [30, 31]. Briefly, $1 \mathrm{ml}$ of $80 \%$ ethanol was added to $\sim 5 \mathrm{mg}$ freeze-dried cells, stirred vigorously for $5 \mathrm{~min}$, incubated for $15 \mathrm{~min}$ at $68^{\circ} \mathrm{C}$, and then centrifuged for $5 \mathrm{~min}$ at $8,000 \mathrm{~g}$. The supernatant was collected and merged after three times of extraction, and evaporated at $85^{\circ} \mathrm{C}$ to $\sim 0.3 \mathrm{ml}$, made up to a total volume of $1 \mathrm{ml}$ with distilled water and used for the soluble sugar analysis. $0.2 \mathrm{ml}$ sample was mixed with $1 \mathrm{ml}$ of anthrone solution ( $2 \mathrm{~g}$ anthrone in $1 \mathrm{~L} 72 \%(\mathrm{v} / \mathrm{v}) \mathrm{H}_{2} \mathrm{SO}_{4}$ )and incubated at $100{ }^{\circ} \mathrm{C}$ for $8 \mathrm{~min}$, and the absorbance under 625 $\mathrm{nm}$ was detected. Glucose was used as standard.

\section{Total protein analysis}

Total protein content was determined as previously described [24]. Briefly, $\sim 5 \mathrm{mg}$ of freeze-dried algal powder was hydrolyzed in $100 \mu \mathrm{L}$ of $1 \mathrm{M} \mathrm{NaOH}$ and then incubated in a water bath at $80{ }^{\circ} \mathrm{C}$ for $10 \mathrm{~min}$. Following this, $900 \mu \mathrm{L} \mathrm{H}_{2} \mathrm{O}$ was added to the hydrolysate to bring the volume to $1 \mathrm{~mL}$. The mixture was centrifuged for $15 \mathrm{~min}$ at $12,000 \mathrm{~g}$ and the supernatant was recovered. After three times of extraction, all the resulted supernatants were merged, and analyzed using a bicinchoninic acid protein assay kit (cat no. P0010S). Bovine serum albumin was used as the standard.

\section{Determine of nitrate concentration in the medium}

The concentration of nitrate in the medium was determined with a Multi N/C 2100S Analyzer (Analytikjena, Germany) equipped with a solid-state electrochemical detector (ChD). Sodium nitrate was used as the standard. The injection volume was $250 \mu \mathrm{L}$ and the linear range was $0.2-5 \mathrm{mg} \mathrm{L}^{-1}$. The temperature of the combustion tube was controlled at $800{ }^{\circ} \mathrm{C}$, and the maximum integration time was $200 \mathrm{~s}$.

\section{Statistical analysis}

Each treatment was conducted in 3 replications. Student t-test were used to detect the significance of differences among samples, and the statistical significance level was set at $P$-value $<0.05$.

\section{Abbreviations}

CDW: Cell dry weight; FL: Fractional labeling; $\mathrm{HC}: ~ 2,000 \mathrm{ppm} \mathrm{CO}_{2}$; MDV: Mass isotopomer distribution vector; NC: $400 \mathrm{ppm}$ of $\mathrm{CO}_{2}$

\section{Acknowledgements \\ Not applicable.}

Authors' contributions

AYH carried out the experiments, performed the data analysis and drafted the manuscript. SCW prepared the samples and participated in data analysis. WHG performed the data analysis. YXL cultured the P. tricornutum. XJX prepared the samples. GCW conceived of the study, and drafted the manuscript. All authors read and approved the manuscript.

\section{Funding}

This work was supported by the National Natural Science Foundation of China (grant number 41876158, 41806171), the National Key R\&D Program of China (2018YFD0901501-1), Haikou Marine Economic Demonstration City Industry Chain Collaborative Innovation Project (HHCL201811), Tianjin Marine Economic Demonstration (BHSF2017-21).

\section{Availability of data and materials}

The datasets used and/or analysed during the current study are available from the corresponding author on reasonable request.

Ethics approval and consent to participate

Not applicable.

Consent for publication

Not applicable.

Competing interests

The authors declare that they have no competing interests.

\section{Author details}

${ }^{1}$ Key Laboratory of Experimental Marine Biology, Institute of Oceanology, Chinese Academy of Sciences, Qingdao 266071, China. ${ }^{2}$ Laboratory for Marine Biology and Biotechnology, Qingdao National Laboratory for Marine Science and Technology, Qingdao 266071, China. ${ }^{3}$ Center for Ocean Mega-Science, Chinese Academy of Sciences, 7 Nanhai Road, Qingdao 266071, China.

Received: 18 March 2019 Accepted: 9 July 2019

Published online: 26 July 2019

References

1. Gao K, Xu J, Gao G, Li Y, Hutchins DA. Rising $\mathrm{CO}_{2}$ and increased light exposure synergistically reduce marine primary productivity. Nat Clim Chang. 2012;2:519-23.

2. Raven JA. Effects on marine algae of changed seawater chemistry with increasing atmospheric $\mathrm{CO}_{2}$. Biol Environ Proc R Irish Acad. 2011;111B:1-17.

3. Millero FJ, Woosley R, Ditrolio B, Waters J. Effect of ocean acidification on the speciation of metals in seawater. Oceanography. 2009:22:72-85.

4. Riebesell U, Schulz KG, Bellerby RG, Botros M, Fritsche P, Meyerhöfer M, Neill C, Nondal G, Oschlies A, Wohlers J. Enhanced biological carbon consumption in a high $\mathrm{CO}_{2}$ ocean. Nature. 2007;450:545-8. 
5. Field C, Behrenfeld M, Randerson J, Falkowski P. Primary production of the biosphere: integrating terrestrial and oceanic components. Science. 1998; 281:237-40.

6. Falkowski $\mathrm{P}$, Barber $\mathrm{R}$, Smetacek V. Biogeochemical controls and feedbacks on ocean primary production. Science. 1998;281:200-6.

7. Leon R, Fernandez E. Nuclear transformation of eukaryotic microalgae historical overview, achievements and problems. Transgenic Microalgae as Green Cell Factories. 2007:616:1-11.

8. Bowler C, Allen AE, Badger JH, Grimwood J, Jabbari K, Kuo A, Maheswari U, Martens C, Maumus F, Otillar RP. The Phaeodactylum genome reveals the evolutionary history of diatom genomes. Nature. 2008;456:239-44.

9. Patil V, Reitan KI, Knutsen G, Mortensen LM, Källqvist T, Olsen E, Vogt G, Gislerød HR. Microalgae as source of polyunsaturated fatty acids for aquaculture. Curr Top Plant Biol. 2005;6(6):57-65.

10. Alipanah L, Rohloff J, Winge $\mathrm{P}$, Bones AM, Brembu T. Whole-cell response to nitrogen deprivation in the diatom Phaeodactylum tricornutum. J Exp Bot. 2015;66:6281-96.

11. Gateau H, Solymosi K, Marchand J, Schoefs B. Carotenoids of microalgae used in food industry and medicine. Mini-Rev Med Chem. 2017;17:1140-72.

12. Wu Y, Gao K, Riebesell U. $\mathrm{CO}_{2}$-induced seawater acidification affects physiological performance of the marine diatom Phaeodactylum tricornutum. Biogeosciences. 2010;7:2915-23.

13. Li F, Beardall J, Collins S, Gao K. Decreased photosynthesis and growth with reduced respiration in the model diatom Phaeodactylum tricornutum grown under elevated $\mathrm{CO}_{2}$ over 1800 generations. Glob Chang Biol. 2016.

14. Li W, Gao K, Beardall J. Interactive effects of ocean acidification and nitrogen-limitation on the diatom Phaeodacty/um tricornutum. PLoS One. 2012; $7:$ :51590

15. Heydarizadeh $P$, Veldl B, Huang B, Lukomska E, Wielgosz-Collin G, CouzinetMossion A, Bougaran G, Marchand J, Schoefs B. Carbon orientation in the diatom Phaeodacty/um tricornutum: the effects of carbon limitation and photon flux density. Front Plant Sci. 2019;10:471

16. Heydarizadeh P, Boureba W, Zahedi M, Huang B, Moreau B, Lukomska E, Couzinet-Mossion A, Wielgosz-Collin G, Martin-Jezequel V, Bougaran G, et al. Response of $\mathrm{CO}_{2}$-starved diatom Phaeodactylum tricornutum to light intensity transition. Philosophical Transactions of the Royal Society BBiological Sciences. 2017:372:20160396.

17. Levering J, Dupont CL, Allen AE, Palsson BO, Zengler K. Integrated regulatory and metabolic networks of the marine diatom Phaeodactylum tricornutum predict the response to rising $\mathrm{CO}_{2}$ levels. Msystems. 2017;2: e00142-16.

18. Wu SC, Huang AY, Zhang BY, Huan L, Zhao PP, Lin AP, Wang GC. Enzyme activity highlights the importance of the oxidative pentose phosphate pathway in lipid accumulation and growth of Phaeodactylum tricornutum under $\mathrm{CO}_{2}$ concentration. Biotechnol Biofuels. 2015;8:78.

19. Huang A, Liu L, Yang C, Wang G. Phaeodactylum tricornutum photorespiration takes part in glycerol metabolism and is important for nitrogen-limited response. Biotechnol Biofuels. 2015:8:73.

20. Harrison P, Waters R, Taylor F. A broad spectrum artificial sea water medium for coastal and open ocean phytoplankton1. J Phycol. 1980;16:28-35.

21. Guillard R. Culture of phytoplankton for feeding marine invertebrates. Cult Mar Invert Animals. 1975;26:C60.

22. Xie X, Huang A, Gu W, Zang Z, Pan G, Gao S, He L, Zhang B, Niu J, Lin A, Wang $G$. Photorespiration participates in the assimilation of acetate in Chlorella sorokiniana under high light. New Phytol. 2016;209:987-98.

23. Xiong $\mathrm{W}$, Liu L, Wu C, Yang C, Wu Q. ${ }^{13} \mathrm{C}$-tracer and gas chromatography-mass spectrometry analyses reveal metabolic flux distribution in the oleaginous microalga Chlorella protothecoides. Plant Physiol. 2010;154:1001-11.

24. Allen DK, Shachar-Hill Y, Ohlrogge JB. Compartment-specific labeling information in ${ }^{13} \mathrm{C}$ metabolic flux analysis of plants. Phytochemistry. 2007;68: 2197-210.

25. Nanchen A, Fuhrer T, Sauer U. Determination of metabolic flux ratios from ${ }^{13} \mathrm{C}$-experiments and gas chromatography-mass spectrometry data. Methods Mol Biol. 2007;358:92.

26. Huang A, Liu L, Zhao P, Yang C, Wang GC. Metabolic flux ratio analysis and cell staining suggest the existence of $C_{4}$ photosynthesis in Phaeodactylum tricornutum. J Appl Microbiol. 2016;120:705-13.

27. Fischer E, Sauer U. Metabolic flux profiling of Escherichia coli mutants in central carbon metabolism using GC-MS. Eur J Biochem. 2003:270:880-91.
28. Bligh EG, Dyer WJ. A rapid method of total lipid extraction and purification. Can J Biochem Physiol. 1959:37:911-7.

29. Huang A, Sun L, Wu S, Liu C, Zhao P, Xie X, Wang G. Utilization of glucose and acetate by Chlorella and the effect of multiple factors on cell composition. J Appl Phycol. 2017;29:23-33.

30. Branyikova I, Marsalkova B, Doucha J, Branyik T, Bisova K, Zachleder V, Vitova M. Microalgae--novel highly efficient starch producers. Biotechnol Bioeng. 2011;108:766-76.

31. Huan L, Xie X, Zheng Z, Sun F, Wu S, Li M, Gao S, Gu W, Wang G. Positive correlation between PSI response and oxidative pentose phosphate pathway activity during salt stress in the intertidal macroalgae. Plant Cell Physiol. 2014;(8):55, 1395-1403.

\section{Publisher's Note}

Springer Nature remains neutral with regard to jurisdictional claims in published maps and institutional affiliations.
Ready to submit your research? Choose BMC and benefit from:

- fast, convenient online submission

- thorough peer review by experienced researchers in your field

- rapid publication on acceptance

- support for research data, including large and complex data types

- gold Open Access which fosters wider collaboration and increased citations

- maximum visibility for your research: over $100 \mathrm{M}$ website views per year

At BMC, research is always in progress.

Learn more biomedcentral.com/submissions 